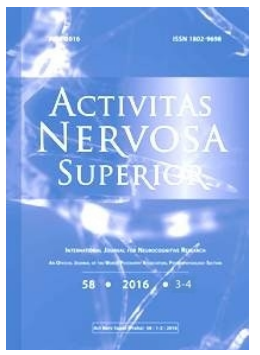

\title{
SYNESTHETIC ASSOCIATIONS AND PSYCHOPATHOLOGICAL SYMPTOMS: PRELIMINARY EVIDENCE IN YOUNG WOMEN
}

\author{
Marcel Neckar, Petr Bob* \\ Center for Neuropsychiatric Research of Traumatic Stress, Department of Psychiatry and UHSL, First Faculty of \\ Medicine, Charles University, Prague, Czech Republic
}

\begin{abstract}
Synesthesia is a neuropsychological condition in which stimulation of one sensory modality or cognitive pathway is associated with unusual experiences in a different unstimulated modality. In this context a purpose of this study is to find relationships between word-color associations and psychopathological symptoms of anxiety (SAS), depression (BDI-II), alexithymia (TAS-20) and symptoms of traumatic stress (TSC-40) in 43 healthy young women (mean age 18.25). Results of this study show that colors associated to specific words have significant correlations with symptoms of anxiety, depression, alexithymia and symptoms of traumatic stress. Sum of scores related to color associations to these words create subscales that are significantly correlated with BDI-II (Spearman R= -0.60), SAS (-0.44), TAS-20 (-0.70) and TSC-40 $(-0.64) ; \mathrm{p}<0.01$. The results indicate specific synesthetic-like mechanisms in association processes specifically linked to psychopathological thinking, feelings and imagination.
\end{abstract}

Key words: Alexithymia; Anxiety; Word associations; Colors; Depression; Stress; Synesthesia

\section{INTRODUCTION}

Synesthesia is a neuropsychological condition in which stimulation of one sensory modality or cognitive pathway is associated with unusual experiences in a different unstimulated modality, for example, hearing a sound may evoke seeing a color (Martino \& Marks, 2001; Eagleman \& Goodale, 2009; Ward, 2013). The first reported case of synesthesia was published in 1812 by Sachs, who documented colored sequences of vowels and music and later Fechner reported colored letter photisms (Jewanski, Day \& Ward, 2009; Jewanski et al., 2011). Later research after the Second World War documented growing evidence about synesthetic phenomena and recent findings show that synesthesia is a phenomenon related to various forms of inter-sensory connections from which most frequent form is experience of colored hearing (Martino \& Marks, 2001; Nunn et al., 2002; Simner \& Hubbard, 2013). For example, it has been documented that higher sounds evoke images of lighter and brighter colors and vice versa (Marks, 1978, 2011; Kuhbandner \& Pekrun, 2013).

*Correspondence to: Petr Bob, e-mail: petrbob@netscape.net

Received September 20, 2016; accepted October 29, 2016; Act Nerv Super 58(3-4), 78-83; ISSN-1802-9698 
Recent studies indicate that phenomenon of synesthesia may be also related to various forms of associative connections as for example grapheme-color synesthesia (Marks, 1978; Cohen, 2005, Ward, 2013). In this context it has been reported that lighter colors are more frequently associated with positive emotional meanings (e.g. happy, good) and certain color specific associations were found for red color ("strong" and "angry"), blue ("good"), green ("strong"), purple ("sad") (Dailey et al., 1997; Kadosh et al., 2005; Okubo \& Ishikawa, 2011).

According to recent findings synesthesia in its mild forms may have relatively high prevalence in population which according to some reported data may be at about 30-50\% (Cytowic, 2002; Campen \& Froger, 2003; Simner \& Hubbard, 2013). In this context a purpose of this study is to assess mild forms of synesthetic experience using novel method of wordcolor associations which is based on emotional response to words that according to their emotional meaning may be specifically associated with darker or lighter color and quantified on a Likert scale. This method in context of other findings suggest a hypothesis that associated colors as related to more specific emotions in response to certain specific emotional words could be related to psychopathological processes related to depression, anxiety, alexithymia and stress symptoms.

\section{PARTICIPANTS AND METHOD}

\subsection{Participants}

Group of participants consisted of 43 healthy young women (Mean age=18.25; SD=0.86, age range 17-19) with high school education. All participants signed informed consent and the study was approved by Charles University ethical committee.

\subsection{Methods}

\section{Assessment of color-word associations}

The method of color-world associations proposed for the purpose of this study is based on emotional response to words that according to their emotional meaning may be specifically associated with lighter or darker color and quantified on color scale from 1 to 10 (Figure 1). In the assessment, as a response to a stimulus words a participant provides spontaneous association of a color according to the scale on Figure 1. The words include usual words but also critical words which usually have particular psychological significance that may cause association disturbances (Jung, 1910; Kondas, 1989). The critical words are designed to recall previous affective associations that modulate new defensive reactions and lead to significant physiological response (Jung, 1910). During the experiment the standard list of 25 stimulus words plus 3 added words (love, sex, punishment) were presented in the following order (critical words in italic): 1. brook, 2. lion, 3. book, 4. dark, 5. love, 6. child, 6. love, 7. table, 8. head, 9. death, 10. boy, 11. illness, 12. hand, 13. mountain, 14. sex, 15. crying, 16. needle, 17. family, 18. cheese, 19. moon, 20. fear, 21. window, 22. street, 23. punishment, 24. salt, 25. man, 26. anger, 27. soldier, 28. doctor. To each stimulus words were associated 3 colors in a sequence which describes the word. For scoring is used mean score of 3 colors associated to the word, first associated color and maximum difference between darkest and lightest associated colors.

Beck Depression Inventory (BDI-II)

For the assessment of depressive symptoms was used Czech version of Beck depression inventory (Beck et al., 1996) that represents 21-items questionnaire for assessing depression (Cronbach's alpha 0.89 , test-retest reliability after week 0.85 ). Subjects indicate degree of their 
experience of depressive symptoms on 4-point Likert scale. The scale is sensitive to changes of the mental state of the individual in the course of time.

Self-Rating Anxiety Scale (SAS)

Levels of anxiety symptoms were assessed using the Czech version of The Zung Self-Rating Anxiety Scale (Cronbach's alpha 0.89, test-retest reliability after week 0.85 ) (Zung, 1971). The SAS is 20-item self-reporting questionnaire focused on the most common general anxiety symptoms. Each question is scored on 4-point Likert scale from 1 to 4 .

Toronto Alexithymia Scale (TAS-20)

Alexithymia was assessed using the validated Czech version of the 20-item Toronto Alexithymia Scale (Cronbach's alpha 0.81, test-retest reliability after 1 week 0.77) (Bagby et al., 1994). Each question is scored on a five-point Likert scale (1-5) and the TAS total score has range from 20 to 100 .

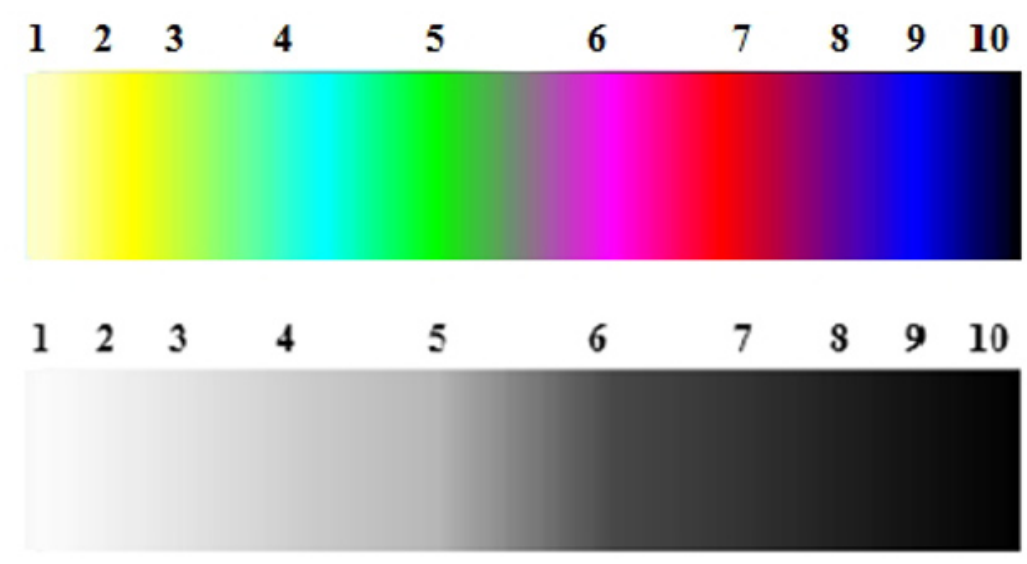

Figure 1. Color scale used for measurement of color associations in response to word stimuli, which in black-white projection provides gray continuous Likert scale from white to black (110).

\section{Trauma Symptoms Checklist (TSC-40)}

Symptoms of traumatic stress were assessed using Trauma Symptom Checklist (Briere, 1996). TSC-40 is a self-reported questionnaire with 40 items scored on a 4-point Likert scale (total score from 0 to 120). TSC-40 evaluates stress symptoms in adult individuals associated with childhood or adult traumatic experiences and measures aspects of posttraumatic stress and other symptom clusters found in some traumatized individuals. The scale includes subscales for dissociation, anxiety, depression, sexual abuse trauma index (SATI), sleep disturbances and sexual problems. The Czech version of the TSC-40 has high reliability and internal consistency (Cronbach's alpha 0.91 , test-retest reliability after one week 0.88 ).

\section{Statistical methods}

Statistical evaluation of the results of the color-word associations and other psychometric measures included descriptive statistics and Spearman correlation coefficients. All the 
methods of statistical evaluation were performed using the software package Statistica version 6.

\section{RESULTS}

Results of descriptive statistic indicate a tendency to link level of darkness on scale of colors (from white 0 to black 10) with words generally perceived as negative Anger (Mean=8.20), Punishment (Mean=7.72), Fear (Mean=7.94), Death (Mean=7.65), Disease (Mean=7.64), Crying (Mean=6.97) on the other hand the less "dark" (lighter) scores were for example linked to words Child (Mean=4.07) and Family (Mean=4.69).

In addition the data show some significant correlations of means, first associated color (1) and the maximum difference of the lightest and darkest associated color (dif.) with psychopathological symptoms of depression, anxiety, alexithymia and traumatic stress. In statistical analysis following significant relationships were found:

Associated color score to the word Child (mean) indicates relatively high negative Spearman correlations with TAS-20 (-0.47; p<0.01), BDI-II $(-0.33 ; \mathrm{p}<0.05)$ and TSC-40 $(-0.36$; $\mathrm{p}<0.05)$, which suggest a link between level of lightness of associated color and symptoms of alexithymia, depression and symptoms of traumatic stress. Child (1) manifests negative correlations with TAS-20 (-0.55; $\mathrm{p}<0.01)$, BDI-II $(-0.33 ; \mathrm{p}<0.05)$, SAS $(-0.35 ; \mathrm{p}<0.05)$ and TSC-40 $(-0.40 ; \mathrm{p}<0.01)$ which also suggest a link between level of lightness of associated color to child and the psychopathological symptoms.

First associated color to word Head (1) manifests negative correlations with TAS-20 (-0.31; $\mathrm{p}<0.05)$, SAS $(-0.39 ; \mathrm{p}<0.01)$ and TSC-40 $(-0.40 ; \mathrm{p}<0.01)$ which also suggest a link between level of lightness of associated colors and the psychopathological symptoms.

Associated colors to word Boy (mean) are significantly negatively correlated with TAS-20 $(\mathrm{r}=-0.49 ; \mathrm{p}<0.01)$ and Boy (dif) are significantly negatively correlated with TAS-20 ( $\mathrm{r}=-0.32$; $\mathrm{p}<0.05)$ and BDI-II $(-0.31 ; \mathrm{p}<0.05)$ which suggests that lighter associations to this word are linked to the symptoms. Hand (1) also manifests negative correlations with BDI-II ( $\mathrm{r}=-0.36$; $\mathrm{p}<0.05)$ and the link between higher lightness level and depressive symptoms is also documented by significant negative correlation between sex (1) and BDI-II $(-0.32 ; \mathrm{p}<0.05)$. Salt (mean) manifests negative correlations with TSC-40 $(-0.41 ; \mathrm{p}<0.01)$ and Salt $(1)$ that also manifests negative correlations with TSC-40 (-0.33). Month (mean) has positive correlation with TAS-20 $(0.36 ; \mathrm{p}<0.05)$ and TSC-40 $(0.31 ; \mathrm{p}<0.05)$. Other correlations are Family $(1)$ with TAS-20 (-0.33; $\mathrm{p}<0.05)$, Cheese (mean) with TSC-40 $(-0.30 ; \mathrm{p}<0.05)$ and Fear (1) with BDI-II ($0.45 ; \mathrm{p}<0.01)$.

With respect to these results we have found specific words associated with depression [Child (mean), Child (1), Boy (dif), Hand (1), sex (1), Fear (1)], anxiety [Child (1), Head (1)], alexithymia [Child (mean), Child (1), Head (1), Boy (mean), Boy (dif), Month (mean)- inverse score, Family (1)] and stress symptoms [Child (mean), Child (1), Head (1), Salt (mean), Salt (1), Month (mean)- inverse score, Cheese (mean)]. Sum of scores related to these specific words provide subscales that link the quantified projective associations with assessed psychopathological symptoms. Color-word subscale for depression (CWDep) shows highly significant correlation with BDI-II (Spearman $\mathrm{R}=-0.60, \mathrm{p}<0.01$ ), Color-word subscale for anxiety (CWAnx) shows highly significant correlation with SAS $(-0.44, \mathrm{p}<0.01)$, Color-word subscale for alexithymia (CWAlex) shows highly significant correlation with TAS-20 (-0.70, $\mathrm{p}<0.01$ ), and Color-word subscale for symptoms for traumatic stress (CWStress) shows highly significant correlation with TSC-40 (-0.64, $\mathrm{p}<0.01)$. 


\section{CONCLUSION}

The results are in agreement with previous reported studies suggesting that lighter colors are more frequently associated with positive emotional meanings (Dailey et al., 1997; Kadosh et al., 2005; Okubo \& Ishikawa, 2011). In addition the results indicate significant relationships of color-word associations to some specific words with depression, anxiety, alexithymia and symptoms of traumatic stress. For example, most significant relationship has been found between lighter associations of colors to word "child" with psychopathological symptoms of anxiety, depression, alexithymia and symptoms of traumatic stress. This finding suggests that young women who see child in light colors have higher levels of psychopathological symptoms and on the other hand tendency to see child in darker colors in young women of this age is more associated with mental health. This finding likely corresponds to understanding of early maternity as a negative factor (Fraser et al., 1995; Lewis et al., 2009).

Other results of this study also show specific relationships between the scores of associated colors on the color scale and psychopathological manifestations linked to depression, anxiety, alexithymia and stress symptoms. These results are in accordance with existing findings in context of the so-called metaphorical synesthesia (Galeyev, 2007). In this metaphorical context synesthetic experiences are closely associated to typical patterns of memory that create context specific associations consolidated in the hippocampus and other structures (Ramachandran \& Hubbard, 2001; Cytowic, 2002; Simner, 2013).

Altogether results of this study provide promising data for quantification of projective assessments using color-word associations and further research in large age and gender specific samples likely might be promissing to develop quantified color-word projective assessment tools.

\section{ACKNOWLEDGEMENT}

The study was supported by the Project GACR P407/12/1957.

\section{REFERENCES}

Bagby, R. M., Parker, J. D. A. \& Taylor, G. J. (1994). The twenty-item Toronto Alexithymia Scale-I. Item selection and cross-validation of the factor structure. Journal of Psychosomatic Research, 38, 23-32.

Beck, A. T., Brown, G., \& Steer, R. A. (1996). Beck Depression Inventory II manual. San Antonio, TX: The Psychological Corporation.

Briere J. Psychometric review of the Trauma Symptom Checklist-40. In Measurement of stress, trauma, and adaptation. Edited by Stamm BH. Lutherville: Sidran Press; 1996.

Campen, C. van, \& Froger, C. (2003). Personal profiles of color synesthesia. Developing a testing method for artists and scientists. Leonardo, 36, 291-294.

Cohen Kadosh, R., Sagiv, N., Linden, D.E., Robertson, L.C., Elinger, G., \& Henik, A. (2005).When blue is larger than red: colors influence numerical cognition in synesthesia. Journal of Cognitive Neuroscience, 17, 1766-73.

Cytowic, R.E. (2002). Synesthesia: A union of the senses. 2nd ed. Cambridge: MIT Press.

Dailey, A., Martindale, C., Borkum, J. (1997). Creativity, synesthesia, and physiognomic perception. Creativity Research Journal, 10, 1-8.

Eagleman, D.M., \& Goodale, M.A. (2009). Why color synesthesia involves more than color. Trends in Cognitive Sciences, 13, 288-92.

Fraser, A.M., Brockert, J.E., \& Ward, R.H. (1995). Association of young maternal age with adverse reproductive outcomes. New England Journal of Medicine, 332, 1113-17.

Galeyev, B.M. (2007). The nature and functions of synesthesia in music. Leonardo, 40, 285-288.

Jewanski, J., Day, S.A. \& Ward, J. 2009. A colorful albino: The first documented case of synesthesia, by Georg Tobias Ludwig Sachs in 1812. Journal of the History of the Neurosciences, 18: 293-303.

Jung, C.G. (1910). The association method. American Journal of Psychology, 31, 219-269. 
Kadosh, R.C., Sagiv, N., Linden, D.E., Robertson, L.C., Elinger, G., Henik, A. (2005). When blue is larger than red: Colors influence numerical cognition in synesthesia. Journal of Cognitive Neuroscience, 17, 1766-1773.

Kondas, O., (1989). Associative experiment. Psychodiagnostika, Bratislava.

Kuhbandner, C., \& Pekrun, R. (2013). Joint effects of emotion and color on memory. Emotion, 13, 375-9.

Lewis, L.N., Hickey, M., Doherty, D.A., \& Skinner, S.R. (2009). How do pregnancy outcomes differ in teenage mothers? A Western Australian study. Medical Journal of Australia, 190, 537-41.

Marks, L.E. (1978). The Unity of the Senses: Interrelations among the Modalities. New York: Academic Press.

Marks, L.E. (2011). Synesthesia: Then and now. Intellectica, 55, 47-80.

Martino, G., \& Marks L.E. (2001). Synesthesia: Strong and Weak. Psychological Science, 10, 61-65.

Nunn, J.A., Gregory, L.J., Brammer M., Williams, S.C.R., Parslow D.M., Morgan, M.J., Morris, R.G., Bullmore, E.T., Baron-Cohen, S., Gray, J.A. (2002). Functional magnetic resonance imaging of synesthesia: activation of V4/V8 by spoken words. Nature Neuroscience, 5, 371-5.

Okubo, M., \& Ishikawa, K. (2011). Automatic semantic association between emotional valence and brightness in the right hemisphere. Cognition \& Emotion, 25, 1273-1280.

Ramachandran, V.S., \& Hubbard, E.M. (2001). Synaesthesia: A window into perception, thought and language. Journal of Consciousness Studies, 8, 3-34.

Simner, J. (2013). Why are there different types of synesthete? Frontiers in Psychology, 2, 558.

Simner, J., \& Hubbard, E. (Eds.) (2013). Oxford Handbook of Synaesthesia. Oxford: Oxford University Press. Ward, J. (2013). Synesthesia. Annual Review of Psychology, 64, 49-75.

Zung, W.W.K. (1971). A rating instrument for anxiety disorders. Psychosomatics, 13, 371-379. 